Article

\title{
Analysis of Symmetric Dual Switch Converter under High Switching Frequency Conditions
}

\author{
Yu Tang ${ }^{1, *}$, Dekai Kong ${ }^{2}$ and Haisheng Tong ${ }^{2}$ \\ 1 State Key Laboratory of Reliability and Intelligence of Electrical Equipment, Hebei University of Technology, \\ Tianjin 300130, China \\ 2 Laboratory of Electromagnetic Field and Electrical Apparatus Reliability of Hebei Province, \\ Hebei University of Technology, Tianjin 300130, China; 201831403030@stu.hebut.edu.cn (D.K.); \\ 201831403056@stu.hebut.edu.cn (H.T.) \\ * Correspondence: 2018040@hebut.edu.cn
}

Received: 12 November 2020; Accepted: 15 December 2020; Published: 18 December 2020

check for updates

\begin{abstract}
Electric vehicle batteries have the problem of low output voltage, so the application of a high-gain converter is a research hotspot. The symmetrical dual-switch high gain converter has the merits of simple structure, low voltage and current stress, and low EMI. Due to the deterioration of circuit performance caused by circuit parasitic parameters under high frequency operating conditions, the former analysis under low frequency condition cannot satisfy the requirements for performance evaluation. To clarify whether the symmetrical dual-switch high-gain converter can maintain its operating characteristics under high-frequency operating conditions, this paper establishes the converter model considering parasitic parameters, and deduces the sneak circuit modes at high frequency. The effects of parasitic parameters at high frequency on voltage gain, switch stress, and symmetrical operating are analyzed, which is beneficial for the selection and optimization of power devices. This paper believes that considering parasitic parameters may reduce the output gain of the symmetrical double-switch high-gain converter considering parasitic parameters under high frequency conditions, increase the switching stress, and affect the symmetry of the circuit operation when the parasitic parameter values are different. Finally, an experimental platform rated on $200 \mathrm{~W}$ with $200 \mathrm{kHz}$ switching frequency is established, and experimental verification is given to verify the analysis.
\end{abstract}

Keywords: symmetrical dual-switch converter; parasitic parameters; high-frequency; characteristic analysis

\section{Introduction}

With the increasingly serious problems of environmental pollution and energy crisis, the new energy vehicle battery has gradually become a research hotspot in the field of new energy vehicles [1]. The new energy vehicle battery refers to a kind of power source that provides driving power source for electric vehicles, electric trains, electric bicycles, and other transportation tools. Compared with battery usage scenarios such as the energy supply of electronic and electrical equipment and the energy storage of energy storage power stations, the new energy vehicle battery has to adapt to the harsh usage scenarios of various vehicles. This requires that the battery should have the characteristics of high energy density, high charge and discharge power, high safety, long life, and low cost. Currently, there are many different types of battery technology systems that can provide power for vehicles, including lead-acid batteries, nickel-metal hydride batteries, lithium-ion batteries, supercapacitors, metal-air batteries, etc.

The new energy vehicle battery is the core component of the power system of electric vehicles, and its comprehensive performance directly affects the performance of electric vehicles. Electric vehicle 
power battery packs provide traction for electric vehicles and supply energy to vehicle equipment—such as vehicle air conditioners, lighting equipment, etc. Due to the slow dynamic response of the new energy vehicle battery and the large voltage variation range, high gain DC/DC converter is necessary to achieve the high DC (direct current) bus voltage. Compared to isolated converter, the non-isolated high gain converter has the merits such as low cost, high efficiency, convenient to control, and so on [2]. Most of the non-isolated high-gain converters are derived from Boost converter. Commonly used voltage lifting method includes cascading, switched capacitor, and coupled inductors [3-5]. The above-mentioned boost converter has problems such as insufficient gain range, excessive switching stress of the device, and EMI (electromagnetic interference) problems. Compared to the high gain converters, the dual switch converter has the advantages of simple structure, high efficiency, low voltage, and current stress [6], while the asymmetric structure induces the unbalance across the power switches. A symmetric dual switch converter is derived to overcome the above disadvantage, it has the advantages of symmetrical circuit structure, internal voltage clamping, small EMI, etc. The symmetric dual switch converter can realize steady-state and dynamic voltage equalization of switches [7].

The symmetric dual switch converter circuit can reflect the working condition of the circuit based on ideal analysis model at low switching frequency [8]. In order to further improve the power density, a higher switching frequency is required. However, high switching frequency is inflicted with higher switching loss that can considerably reduce the power efficiency of power electronic systems [9]. Therefore, the former analysis under low frequency condition cannot satisfy the requirements for performance evaluation. As a result, many researchers considered parasitic components in their analytical models. Investigations into the effect of parasitic components under high frequency conditions can be summarized as the switching performances of MOSFET (metal-oxide-semiconductor field-effect transistor), switching loss, electromagnetic interference problems, the line current total harmonic distortion of Boost PFC (power factor correction) converter, and the voltage gain of the converter [10-14]. In early research, Gutsmann measured the effects of parasitic components in the power electronic systems by circuit simulations [15]. In Reference [16], the parasitic components were researched individually, the effect of parasitic inductance on MOSFET switching characteristics is studied through experiment. Xiong and Murthy-Bellur have analyzed the impacts of parasitic components and also provided solutions [17]. In Reference [18], the sneak circuit modal analysis method is used to analyze the changes in the operating characteristics of the DCM (discontinuous conduction mode) boost converter after considering the parasitic parameters. After analyzing the effect on gain and stress, the feasibility of the sneak circuit analysis method is proved.

Refer to the analysis content and analysis ideas of the above documents, this paper analyzes the sneak circuit and operating characteristics of the symmetrical dual-switch high gain converter considering parasitic parameters at high frequencies. This paper establishes the converter model considering parasitic parameters, and deduces the sneak circuit modes at high frequency. The effects of parasitic parameters at high frequency on voltage gain, switch stress, and symmetrical operating are analyzed, which is beneficial for the selection and optimization of power devices.

The arrangement of this paper is as follows: in Section 2, the converter model considering devices parasitic parameters at high frequency is established. The sneak modes considering the non-ideal device models are established. In Section 3, the influence of parasitic parameters under high-frequency conditions on the voltage gain, switching stress, and symmetrical operating of the converter is analyzed. The influence of parasitic parameters on the symmetrical performance of the circuit is analyzed. In Section 4, experiments are given to verify the theoretical analysis. Section 5 summarizes the full text of this article.

\section{Analysis of Sneak Circuit of Dual-Switch Converter with Parasitic Parameters}

The circuit topology of the symmetric dual switch high-gain converter is shown in Figure 1. The converter performs parallel charge and series discharge of $L_{1}, L_{2}$ by controlling the switch to obtain high voltage gain. Since the voltage of the capacitor is constant in steady-state, the voltage of $S_{2}$ is 
clamped by $C_{01}$ and $C_{i 2}$, and the voltage of $S_{1}$ is clamped by $C_{02}$ and $C_{i 1}$. Due to the symmetry of the structure, the converter can achieve the voltage balance of both switches either in steady-state or dynamic-state.

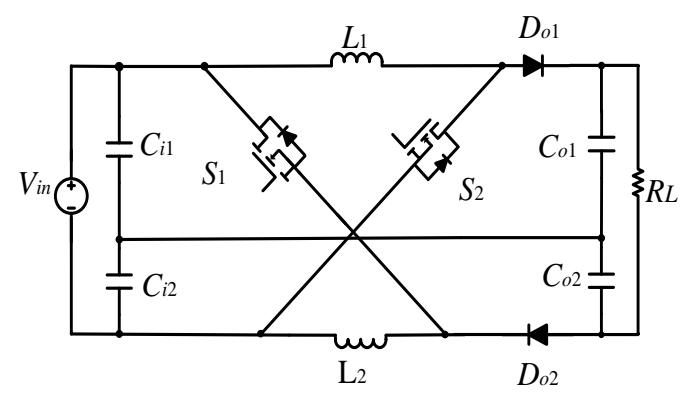

Figure 1. Dual switch step-up DC/DC converter.

For devices in the converter circuit: the inductors $L_{1}, L_{2}$ consider its parasitic resistances $R_{L 1}, R_{L 2}$; diodes $D_{1}, D_{2}$ consider their parasitic capacitors $C_{D 01}, C_{D 02}$; for MOSFET: $C_{d s 1}, C_{d s 2}$ are the parasitic capacitors between the drain-source, $L_{d_{-} i n}, L_{s_{-} i n}$ are the parasitic inductor of the drain and the source. $R_{s}, R_{d}$ are the external equivalent parasitic resistor of the switch. $L_{d \_e x}, L_{s \_} e x$ are the external equivalent parasitic inductors of the switch. For the convenience of calculations, let $L_{d}=L_{d \_i n}+L_{d \_ \text {ex }}, L_{S}=L_{S_{-} i n}+$ $L_{s_{-} e x}$. The converter model after considering parasitic parameters is given in Figure 2.
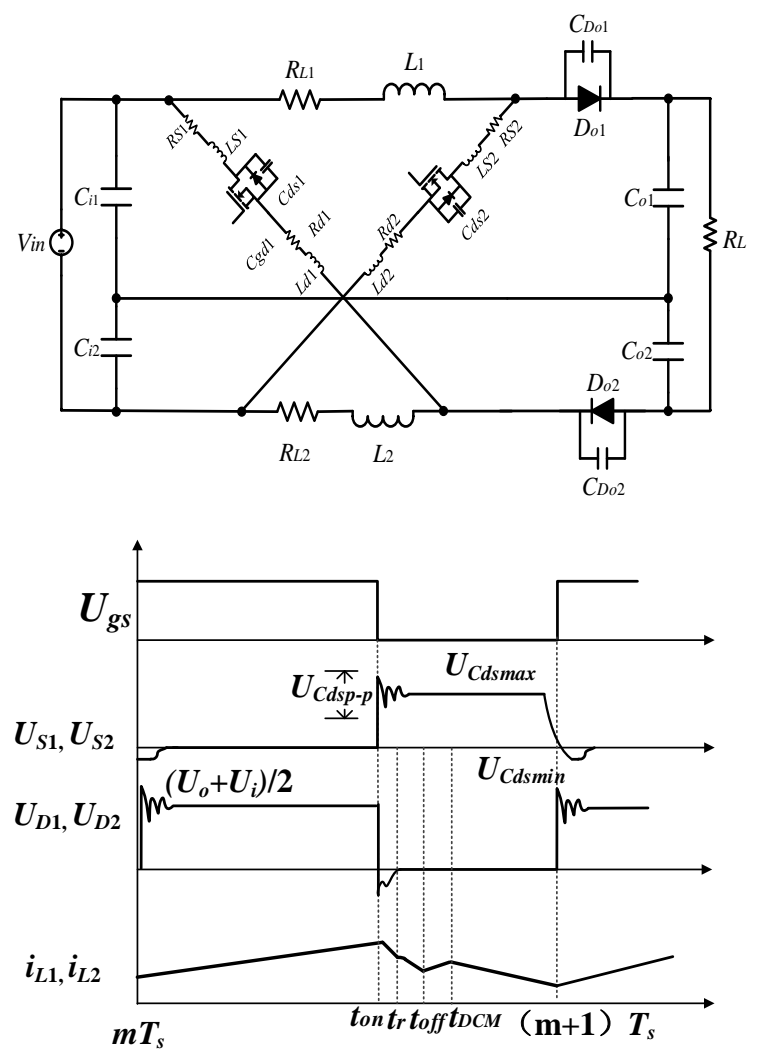

Figure 2. Dual switch step-up DC/DC converter considering parasitic parameters.

Use the mesh combination analysis method to analyze the sneak circuit caused by the parasitic parameters at high frequency. First, establish its undirected graph model as shown in Figure 3 below. 


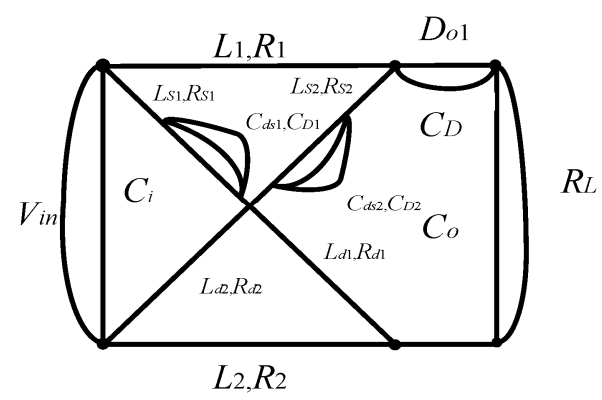

Figure 3. Undirected graph of dual-switch boost converter considering parasitic parameters.

According to the mesh combination analysis method, the maximum number of sub-circuits of the dual-switch converter can be obtained as 236. After removing duplicate sub-circuits, 106 actual sub-circuits are obtained. According to the working principle of the converter, the five effective working modes of the converter are obtained. Comparing these five working modes with the ideal working mode, the three normal modes and two sneak circuit modes caused by parasitic parameters under high-frequency conditions are obtained as follows:

For the convenience of reference, the parameters used in this article are defined as follows: $U_{R s}$ is the terminal voltage of $R_{s} ; U_{R d}$ is the terminal voltage of $R_{d} ; U_{L s}$ is the terminal voltage of $L_{s} ; U_{L d}$ is the terminal voltage of $L_{d} ; U_{C_{d s}}$ is the terminal voltage of $C_{d s}, U_{C_{d s} \max }$ is the maximum value of $U_{C_{d s}}$, $U_{C_{d s} \min }$ is the minimum value of $U_{C d s}, U_{C_{d s p-p}}$ is the peak-to-peak voltage; $I_{R}$ is the current of $R_{s} ; I_{R d}$ is the current of $R_{d} ; I_{L s}$ is the current of $L_{s} ; I_{L d}$ is the current of $L_{d} ; I_{C_{d s}}$ is the current of $C_{d s}$.

\subsection{Analysis of Normal Modes}

Mode $1, t \in\left[m T_{S}, t_{o n}\right]$ : When the gate drive voltage reaches $U_{G}$, the switches are turned on. During this period, the switches $S_{1}, S_{2}$ remain on, and the diodes $D_{1}, D_{2}$ remain off. The power supply $V_{\text {in }}$ charges the inductors $L_{1}, L_{2}$, and the inductor current $i_{L}$ increases linearly. The load side is powered by $C_{01}, C_{02}$. Its equivalent circuit is shown in Figure 4.

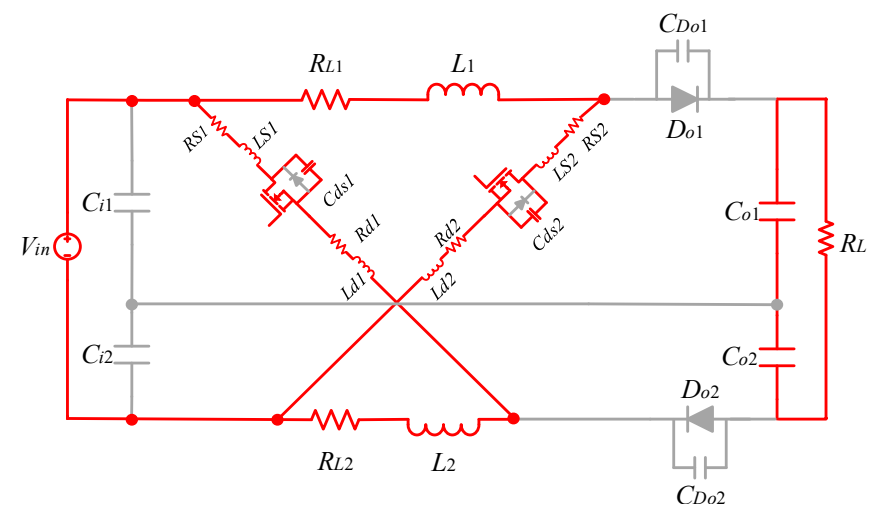

Figure 4. Equivalent circuit of Mode 1.

Mode $2, t \in\left[t_{r}, t_{o f f}\right]$ : At the time $t_{r}$, the diodes $D_{1}, D_{2}$ are still in the conducting state, the energy storage in the power supply and the inductors $L_{1}, L_{2}$ continues to be transferred to the load, and the inductor current $i_{L}$ decreases linearly. At the same time, all the energy stored in the parasitic inductors $L_{d}, L_{s}$ of the MOSFET is released. The equivalent circuit is given in Figure 5. 


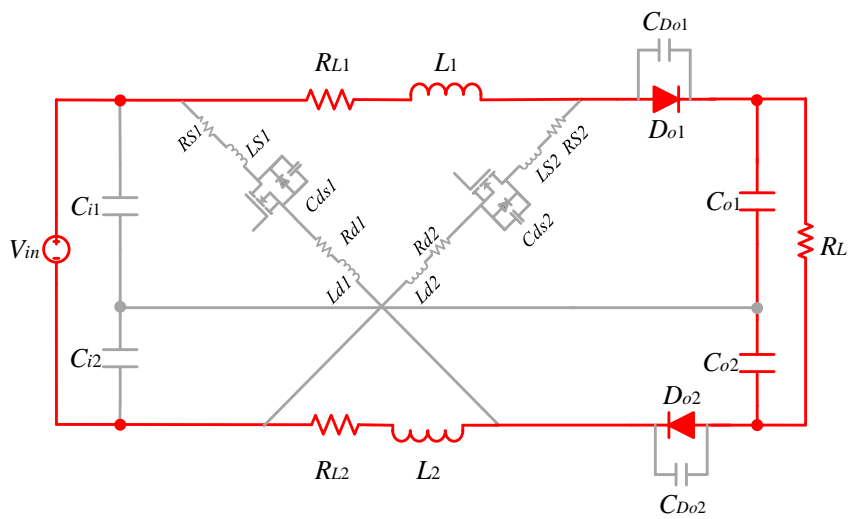

Figure 5. Equivalent circuit of Mode 2.

Mode $3, t \in\left[t_{D C M},(m+1) T_{s}\right]$ : Due to the energy consumption of the resistances in the circuit and the parasitic parameters, the inductor current $i_{L}$ will attenuate to zero at time $t_{D C M}$. At this time, the inductor current can be regarded as zero, and the output capacitors $C_{01}, C_{02}$ continue to provide energy to the load, and their equivalent circuits are shown in Figure 6.

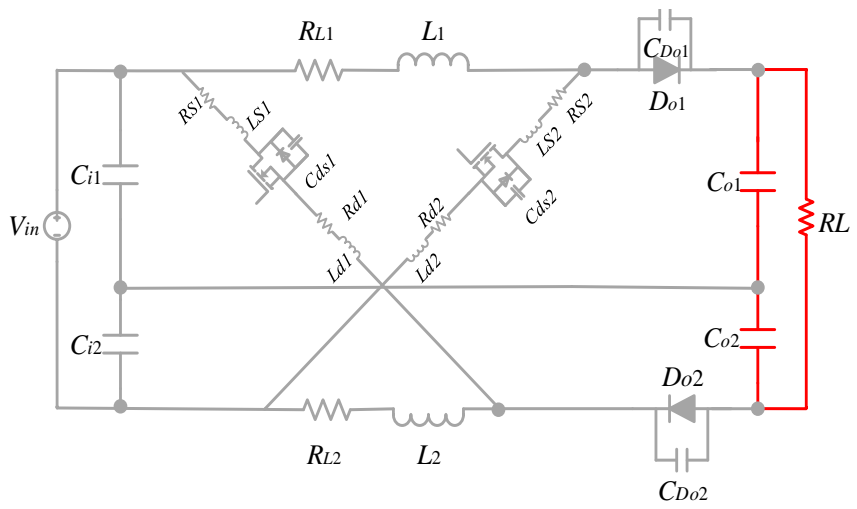

Figure 6. Equivalent circuit of Mode 3.

\subsection{Analysis of Sneak Modes}

Sneak Mode $1, t \in\left[t_{o n}, t_{r}\right]$ : The switches $S_{1}, S_{2}$ are turned off at the time $t_{o n}$, and the inductor current $i_{L}$ is transferred from the switches $S_{1}, S_{2}$ to the diodes $D_{1}, D_{2}$, and the energy is transferred to the load end. At the $t_{o n}$ moment, the voltage across $C_{D 01}$ increases from $U_{C_{D} \min }$ to $U_{C_{d s} \max }$, the voltages across $C_{d s 1}, C_{d s 2}$ increase from $U_{C_{d s} \min }$ to $U_{C_{d s} \max }$. The inductors and the parasitic capacitors in the circuit resonate. The equivalent circuit is shown in Figure 7, and the equations of Sneak Mode 1 can be obtained as

$$
\left\{\begin{array}{c}
i_{L 1_{\mathrm{II}}}=I_{L 1}\left(t_{o n}\right) e^{-\frac{R_{L 1}+R_{L 2}+R_{\mathrm{e} 2}}{L_{1}}\left(t-t_{o n}\right)}+\frac{U_{i}-U_{o}-U_{C_{D} \max }}{R_{L 1}+R_{L 2}+R_{\mathrm{e} 2}}\left[1-e^{-\frac{R_{L 1}+R_{L 2}+R_{\mathrm{e} 2}}{L_{1}}\left(t-t_{o n}\right)}\right] \\
i_{L 2_{\mathrm{II}}}=I_{L 2}\left(t_{o n}\right) e^{-\frac{R_{L 1}+R_{L 2}+R_{\mathrm{e} 1}}{L_{2}}\left(t-t_{o n}\right)}+\frac{U_{i}-U_{o}-U_{C_{D} \max }}{R_{L 1}+R_{L 2}+R_{\mathrm{el}} 1}\left[1-e^{-\frac{R_{L 1}+R_{L 2}+R_{\mathrm{e} 1}}{L_{2}}\left(t-t_{o n}\right)}\right] \\
U_{C_{d s p-p 1}}=2 \frac{U_{C_{d s} 1 \max }+U_{C_{D^{\max }}-U_{o}}}{\omega_{1}^{2} L_{e 1} C_{e 1}} \\
U_{C_{d s p-p 2}}=2 \frac{U_{C_{d s}{ }^{2} \max }+U_{C_{D} \max }-U_{o}}{\omega_{2}^{2} L_{e 2} C_{e 2}} \\
U_{C_{d s} \max }=\frac{U_{o}+U_{i}+U_{C_{D} \max }}{2}-i_{L_{\mathrm{II}}} R_{S}-L \frac{d i_{L_{\mathrm{II}}}}{d t} \\
U_{C_{d s} \min }=\frac{U_{o}+U_{i}+U_{C_{D} \min }}{2}-i_{L_{\mathrm{II}}} R_{S}-L \frac{d i_{L_{\mathrm{II}}}}{d t}
\end{array}\right.
$$




$$
\left\{\begin{array}{l}
C_{e 1}=C_{d s 1}+\frac{C_{g s} C_{g d 1}}{C_{g s 1}+C_{g d 1}}, C_{e 2}=C_{d s 2}+\frac{C_{g s 2} C_{g d 2}}{C_{g s 2}+C_{g d 2}} \\
\omega_{1}=2 \sqrt{1 / L_{e 1} \frac{C_{e 1} C_{o}}{C_{e 1}+C_{o}}}, \omega_{2}=2 \sqrt{1 / L_{e 2} \frac{C_{e 2} C_{o}}{C_{e 2}+C_{o}}}
\end{array}\right.
$$

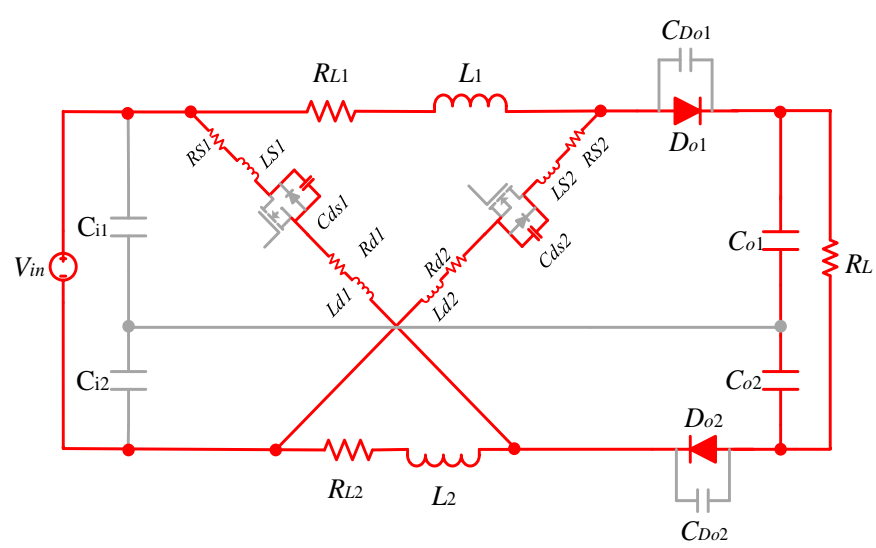

Figure 7. Equivalent circuit of Sneak Mode 1.

It can be seen from the formulas that $U_{C_{d s p-p}}$ is very small compared with $U_{C_{d s} \text { max. If }} U_{C_{d s p-p}}$ is small enough at time $t>t_{o n}$, it can be considered that the operation process of the converter circuit at high frequency will cross the Sneak Mode. Set the boundary value equation as $U_{C_{d s p \_p}} / U_{C_{d s} \max }=\zeta$. When $U_{C_{d s p \_} p} / U_{C_{d s} \max }=\zeta$, the converter can skip Sneak Mode 1 operation.

Sneak Mode 2, $t \in\left[t_{o f f}, t_{D C M}\right]$ : When the $t_{o f f}$ time is reached, the inductor current decreases and then increases in the reverse direction, the parasitic capacitor and the inductor resonate, the voltage across the diode's parasitic capacitor $C_{D}$ discharges from $U_{C_{D} \text { max }}$ to $U_{C_{D} \text { min }}$ and the voltage of the switch parasitic capacitor $C_{d s}$ discharges from $U_{C_{d s} \max }$ to $U_{C_{d s} \min }$. When the discharge voltage reaches the turn-on voltage of diodes, the diodes are turned on, and the converter then enters the reverse recovery process. The equivalent circuit is shown in Figure 8. Similarly, the equations of Sneak Mode 2 can be obtained as

$$
\begin{aligned}
& \left\{\begin{array}{c}
i_{L 1_{\mathrm{IV}}}=\frac{U_{i}-U_{o}-U_{C_{D} \max x}}{\omega_{1}\left(L_{1}+L_{2}+L_{e 2}+L_{q 1}\right)} e^{-\rho_{1}\left(t-t_{o f f}\right)} \sin \omega_{1}\left(t-t_{o f f}\right) \\
i_{L 2_{\mathrm{IV}}}=\frac{U_{i}-U_{o}-U_{C_{D} \operatorname{maxx}}}{\omega_{2}\left(L_{1}+L_{2}+L_{e 1}+L_{q 2}\right)} e^{-\rho_{2}\left(t-t_{o f f}\right)} \sin \omega_{2}\left(t-t_{o f f}\right) \\
U_{C_{D} 01}=U_{i}-U_{o}-\left(U_{i}-U_{o}-U_{C_{D} \max }\right) e^{-\rho_{1}\left(t-t_{o f f}\right)}\left[\cos \omega_{1}\left(t-t_{o f f}\right)+\frac{\rho_{1}}{\omega_{1}} \sin \omega_{1}\left(t-t_{o f f}\right)\right]
\end{array}\right. \\
& \left\{\begin{array}{c}
\rho_{1}=\frac{2 R_{L 1}+R_{\mathrm{e} 1}}{2 L_{1}}, \rho_{2}=\frac{2 R_{L 2}+R_{\mathrm{e} 2}}{2 L_{2}} \\
\omega_{1}=\sqrt{\frac{1}{L_{1}\left(C_{D}+C_{e 1}\right)}-\rho_{1}^{2}}, \omega_{2}=\sqrt{\frac{1}{L_{2}\left(C_{D}+C_{e 2}\right)}-\rho_{2}^{2}} \\
C_{r 1}=C_{D}+C_{e 1}, C_{r 2}=C_{D}+C_{e 2} \\
L_{q 1}=\frac{L_{e 1} C_{e 1} C_{D}-R_{o}^{2}\left[C_{D}^{2}\left(C_{e 1}+C_{o}\right)+C_{o}^{2} C_{r 1}\right]}{\left(C_{r 1}-\omega_{1}^{2} L_{e 1} C_{e 1} C_{D}\right)^{2}+\omega_{1}^{2} R_{o}^{2}\left(C_{e 1} C_{D}+C_{o} C_{r 1}-\omega_{1}^{2} L_{e 1} C_{e 1} C_{D}\right)^{2}} \\
L_{q 2}=\frac{L_{e 2} C_{e 2} C_{D}-R_{o}^{2}\left[C_{D}^{2}\left(C_{e 2}+C_{o}\right)+C_{o}^{2} C_{r 2}\right]}{\left(C_{r 2}-\omega_{2}^{2} L_{e 2} C_{e 2} C_{D}\right)^{2}+\omega_{2}^{2} R_{o}^{2}\left(C_{e 2} C_{D}+C_{o} C_{r 2}-\omega_{2}^{2} L_{e 2} C_{e 2} C_{D}\right)^{2}}
\end{array}\right.
\end{aligned}
$$




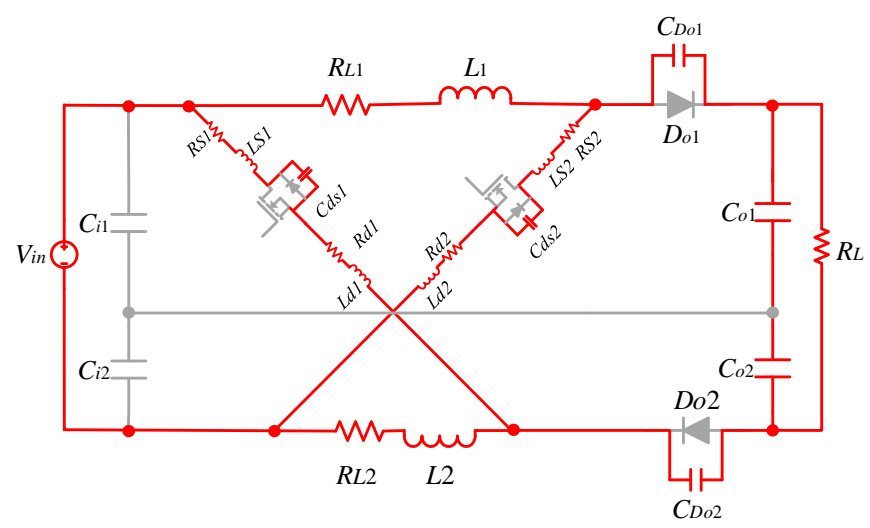

Figure 8. Equivalent circuit of Sneak Mode 2.

The analysis shows that the inductor current $i_{L}$ in Sneak Mode 2 is a sinusoidal wave with resonant angular frequency $\omega$. Substituting the voltage of $C_{D}$ into the previous equation, the voltage expression of $U_{C D}$ can be obtained as

$$
\left\{\begin{array}{c}
U_{C_{D} \min 1}=U_{i}-U_{o}+\left(U_{i}-U_{o}-U_{C_{D} \max }\right) e^{-\rho_{1} \frac{\pi}{\omega_{1}}} \\
U_{C_{D} \min 2}=U_{i}-U_{o}+\left(U_{i}-U_{o}-U_{C_{D} \max }\right) e^{-\rho_{2} \frac{\pi}{\omega_{2}}} \\
U_{C_{D} \max 1}=\left(U_{i}-U_{o}\right)\left(1+e^{-\rho_{1} \frac{\pi}{\omega_{1}}}\right)+\frac{2 U_{o} C_{e 1}}{C_{e 1}+C_{D}} \\
U_{C_{D} \max 2}=\left(U_{i}-U_{o}\right)\left(1+e^{-\rho_{2} \frac{\pi}{\omega_{2}}}\right)+\frac{2 U_{o} C_{e 2}}{C_{e 2}+C_{D}}
\end{array}\right.
$$

From the above analysis of the sneak circuit, considering the parasitic parameters of the devices under high-frequency conditions will cause the converter to resonate due to the parasitic junction capacitors and the inductors in the circuit, which will affect the output characteristic of the converter.

In the DCM mode, the circuit modes operation sequences are Mode 1, Sneak Mode 1, Mode 2, Sneak Mode 2, Mode 3. In the CCM (continuous conduction mode) mode, the circuit modes operation sequences are Mode 1, Sneak Mode 1, Mode 2, Sneak Mode 2. The operation process of the circuit in the CCM mode and the DCM mode is shown in the Figure 9 below.

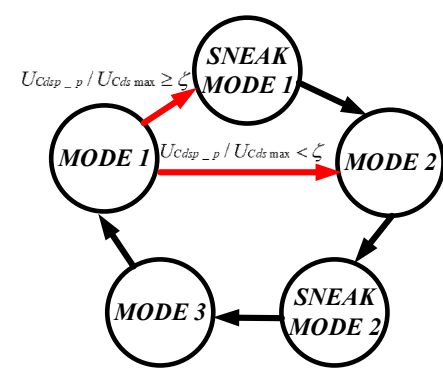

(a)

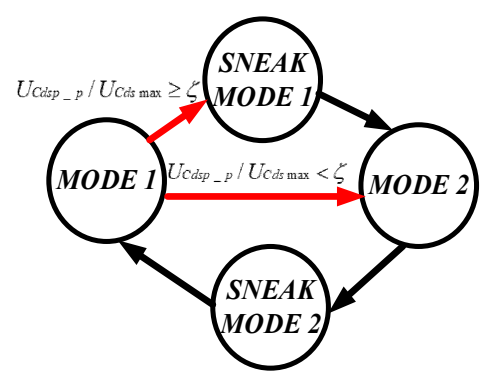

(b)

Figure 9. Operation mode conversion diagrams of the converter under two operating modes. (a) The modes of the converter in DCM (discontinuous conduction mode) mode. (b) The modes of the converter in CCM (continuous conduction mode) mode.

\section{Considering the Influences of Parasitic Parameters on Converter Characteristic}

According to the law of conservation of energy, write the following equation for the column

$$
\left\{\begin{array}{c}
U_{i} \int_{m T_{s}}^{(m+1) T_{s}} i_{L} d t=\frac{U_{o}^{2}}{R_{L}} T_{s}+\int_{m T_{s}}^{(m+1) T_{s}}\left(U_{R_{L} 1}+U_{R_{L} 2}\right) i_{L} d t \\
U_{o} \int_{m T_{s}}^{(m+1) T_{s}} i_{0} d t=\frac{U_{o}^{2}}{R_{L}} T_{s}
\end{array}\right.
$$


During $t \in\left[t_{o n}, t_{o f f}\right]$ the inductor current satisfies the equation as

$$
\int_{t_{o n}}^{t_{o f f}} i_{L} d t=\frac{1}{2} D T_{s} I_{L}\left(t_{o n}\right)=\frac{U_{o}}{R_{L}} T_{S}-2 C_{D}\left(U_{C_{D} \max }-U_{C_{D} \min }\right)
$$

Among them, $D T_{s}=t_{o f f}-t_{o n}$.

\subsection{Effects of Parasitic Parameters on Voltage Gain}

1. In the Ideal Case

According to the volt-second equilibrium principle and the relationship between $i_{L}$ and $i_{D}$ in ideal mode, the voltage gain of an ideal dual-switch step-up converter can be obtained as

$$
M=\frac{U_{o}}{U_{i}}=\frac{1+D}{1-D}
$$

2. Considering Parasitic Parameters

According to the volt-second equilibrium principle and the law of energy conservation, the voltage gain of the dual-switch converter with parasitic parameters can be obtained as follows:

Switch on period:

$$
U_{L 1}=U_{L 2}=U_{i}-U_{R 1}-U_{R_{\mathrm{e}} 2}
$$

Switch off period:

$$
U_{L 1}=U_{L 2}=\frac{1}{2}\left(U_{i}-U_{o}-U_{R_{L} 1}-U_{R_{L} 2}\right)
$$

Simultaneous equations are obtained:

$$
M^{\prime}=\frac{1+D-\left[\frac{\left(R_{S}+R_{d}+R_{L}\right)}{\frac{2 U_{i}}{R_{\mathrm{O}}+}-f_{s} C_{D}\left(U_{C_{D} \min }-U_{C_{D} \max }\right)}+f_{s} L_{e}\right] \frac{1-e^{-2 \rho D / f_{s}}}{R_{S}+R_{d}+R_{L}}}{1-D}
$$

From the above equations, the relationship between input voltage and output voltage is a constant value when the circuit parameters and operating period of the converter are determined in the ideal working state. When the converter considering parasitic parameters, the relationship is an exponentially decreasing expression.

Set the rated parasitic parameters values as follows: $C_{d s}=232 \mathrm{pF}, C_{D}=60 \mathrm{pF}, R_{s}=0.05 \Omega, L_{e}=147$ $\mathrm{nH}$. In the case where the ideal circuit parameter values are unchanged, the influences of the changes in the values of each parasitic parameter on the output gain characteristics of the converter are shown in Figure 10. 


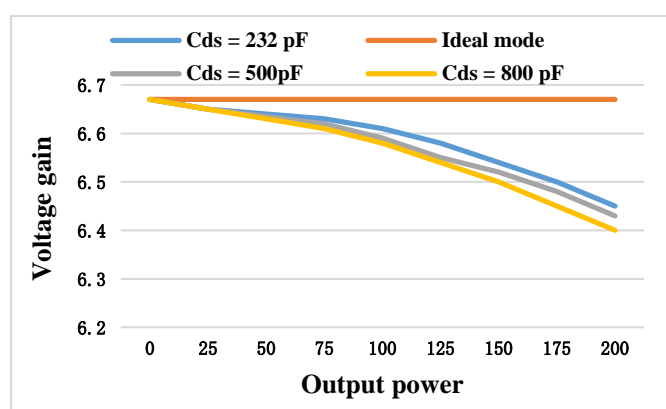

(a)

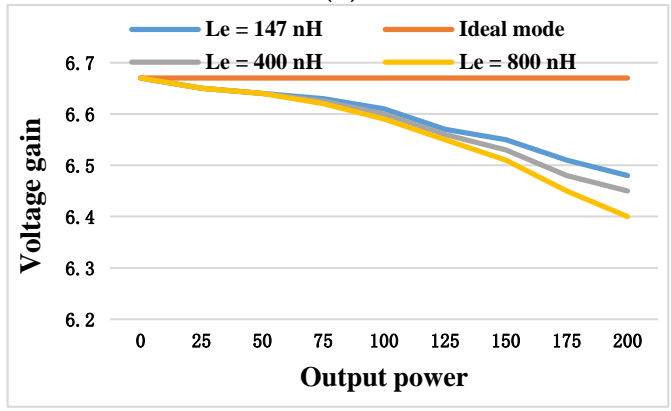

(c)

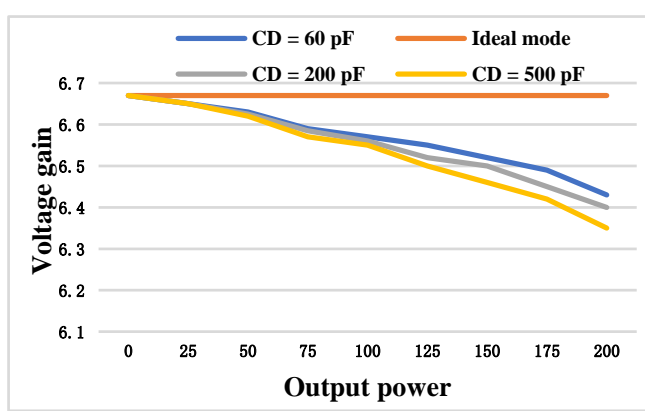

(b)

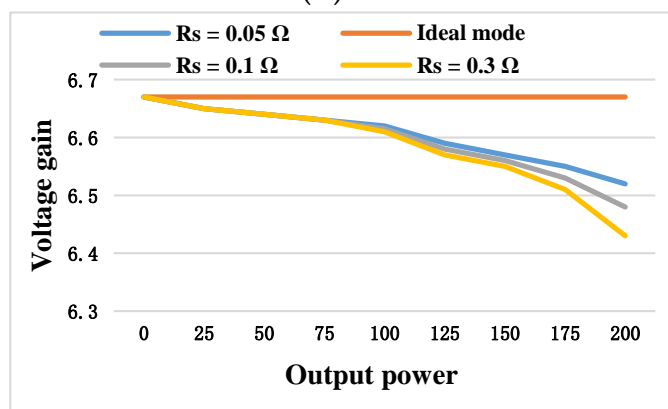

(d)

Figure 10. Comparisons of the influence of various parasitic parameters on the output gain. (a) Influences of numerical value of $C_{d s}$. (b) Influences of numerical value of $C_{D}$. (c) Influences of numerical value of $C_{d s}$. (d) Influences of numerical value of $C_{d s}$.

The above figures show the results that those four parasitic parameters share the common characteristic: the larger the values of the parasitic parameter, the more obvious the effects of reducing the output gain.

\subsection{Effects of Parasitic Parameters on Switch Stress}

List the voltage and current stress of the switching devices in the ideal model and the model considering parasitic parameters as follows:

1. Ideal conditions

$$
\left\{\begin{array}{c}
\overline{I_{S}}=\frac{U_{i}}{L_{1}+L_{2}} D T_{\mathcal{S}} \\
U_{S}=\frac{M U_{i}}{2} \\
\overline{I_{D}}=\frac{U_{i}}{L_{1}+L_{2}} D T_{S} \\
U_{D}=-M U_{i}
\end{array}\right.
$$

2. Conditions considering parasitic parameters

$$
\left\{\begin{array}{c}
\overline{I_{S 1}}=\frac{U_{i}-U_{C_{d s} 1 \min }}{R_{S 1}+R_{L 1}+R_{d 1}}\left(1-e^{-\frac{R_{S 1}+R_{L 1}+R_{d 1}}{L_{1}} t}\right) \\
\overline{I_{S 2}}=\frac{U_{i}-U_{C_{d 5} \min }}{R_{S 2}+R_{L 2}+R_{d 2}}\left(1-e^{-\frac{R_{S 2}+R_{L 2}+R_{d 2} t}{L_{2}} t}\right) \\
U_{S 1}=\frac{U_{o}+U_{i}+U_{C_{D} \max }}{2}-i_{L_{I I}} R_{S}-L \frac{d i_{L_{I I}}}{d t}+\frac{U_{C_{d s} 1 \max }+U_{C_{D} \max }-U_{o}}{\omega_{1}^{2} L_{e 1} C_{e 1}} \\
U_{S 2}=\frac{U_{o}+U_{i}+U_{C_{D} \max }}{2}-i_{L_{I I}} R_{S}-L \frac{d L_{L_{I I}}}{d t}+\frac{U_{C_{d s}} 2 \max +U_{C_{D} \max }-U_{o}}{\omega_{2}^{2} L_{e 2} C_{e 2}} \\
\overline{I_{D}}=\frac{U_{i}-U_{C_{d s} \min }}{R_{S 1}+R_{L 1}+R_{d 1}}\left(1-e^{-\frac{R_{S 1}+R_{L 1}+R_{d 1}}{L_{1}} t}\right) \\
U_{D}=U_{C_{D} \min }
\end{array}\right.
$$


Set the rated parasitic parameter values as follows: $C_{d s}=232 \mathrm{pF}, C_{D}=60 \mathrm{pF}, R_{S}=0.05 \Omega, L_{e}=147$ $\mathrm{nH}$. The voltage stress of the ideal model and the model considering the parasitic parameter are shown in Figure 11 below.

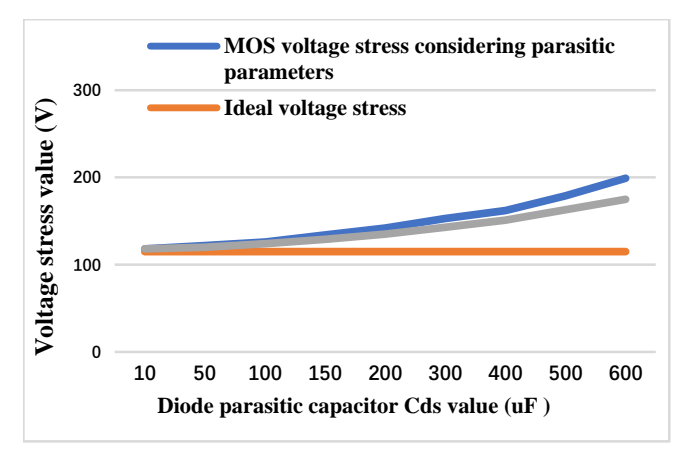

(a)

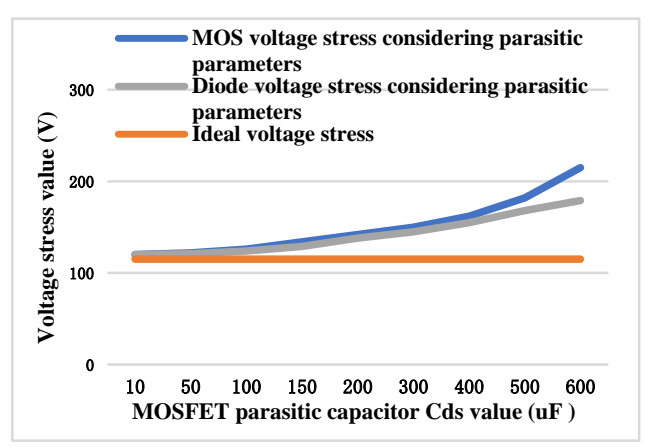

(b)

Figure 11. Comparisons of the influence of various parasitic parameters on the output gain. (a) The effects of the $C_{d s}$ on the switching stress. (b) The effects of $C_{D}$ on switching stress.

It can be seen from the above figures that, compared with the voltage stress under ideal conditions, the voltage stress when considering parasitic parameters of the converter is greater. The larger the values of the parasitic capacitors, the larger the amplitude of the resonance voltage of the switches. If the device selection does not consider the impacts of the inductor current fluctuations and the switching stress differences, it may cause new modes or circuit failures in the circuit, which means the selections of devices in circuits under high-frequency conditions must take the effects of parasitic parameters into account.

\subsection{Influence of Parasitic Parameters Asymmetry on Circuit}

In the ideal model, due to the symmetrical structure of the converter, the voltage balance of the switches $S_{1}, S_{2}$ can be achieved under both steady-state and dynamic conditions, and the centerline has no charge and discharge current. However, if the parasitic parameter values are different for the same type of devices, the symmetric circuit will present an asymmetric working state, which will bring adverse effects on the performance of the converter.

The analysis equations about the voltages of the MOSFET in the sneak modes is re-wrote in this paper to get the expressions of the voltage difference of the parasitic capacitors of the MOSFETs as follows:

$$
\Delta U_{C_{d s}}=\frac{U_{C_{D} 01 \max }-U_{C_{D} 02 \max }}{2}-i_{L_{\mathrm{II}}}\left(R_{s 1}-R_{s 2}\right)-\left(L_{1}-L_{2}\right) \frac{d i_{L_{\mathrm{II}}}}{d t}
$$


The analytical equations for the inductor current and diode voltage in Sneak Mode is re-wrote in this paper to get the difference expressions as follows:

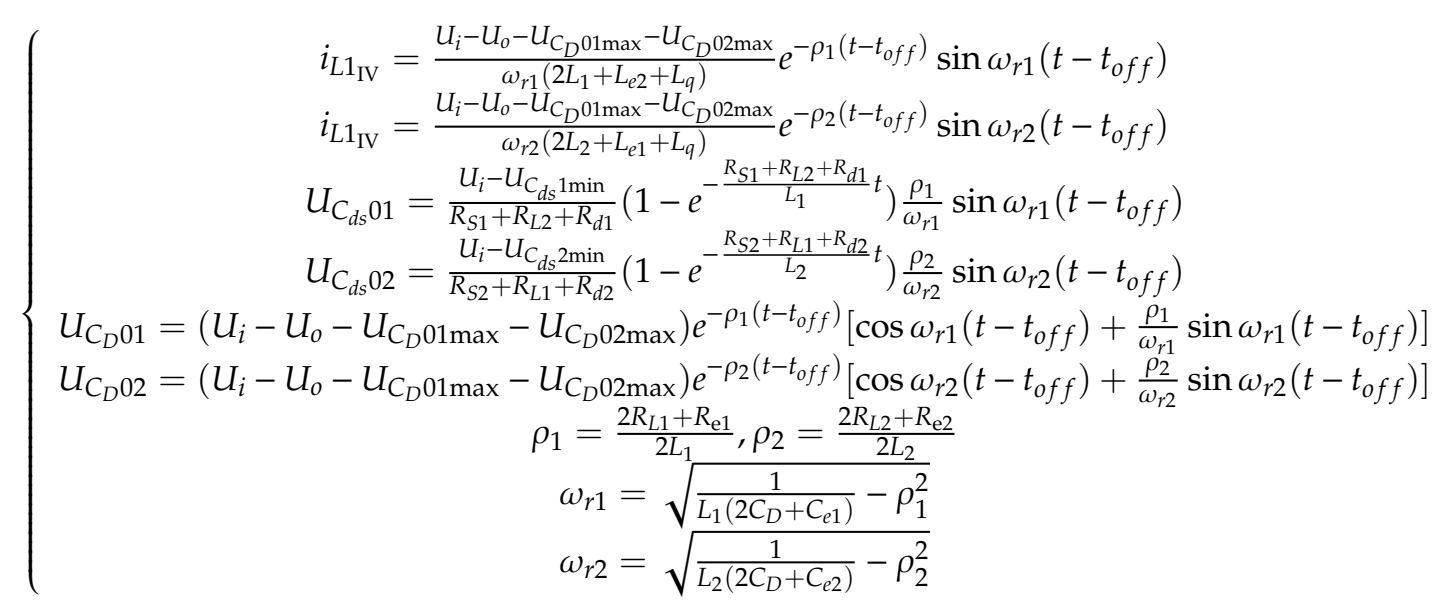

The influences of the parasitic parameters $C_{d s}, C_{D}$ are reflected in the influences on the oscillation frequency $\omega_{r}$ and equivalent inductor $L q$. The influences of the parasitic parameter $R_{L}$ are reflected in the influences on oscillation frequency $\omega_{r}$, equivalent parameter $\rho$, and equivalent inductor $L q$. The change of parasitic parameters will result in different inductor current values of $i_{L 1}, i_{L 2}$, and the occurrence times of the resonance currents, which makes the charge and discharge currents appear in the centerline of the circuit. The two MOSFETs and diodes have different resonance amplitudes and resonance appearance times. The operation symmetry of the circuit is destroyed, which may cause new modalities or circuit failures. Draw the waveform of the stress difference formulas considering the parasitic parameters as shown in Figure 12.

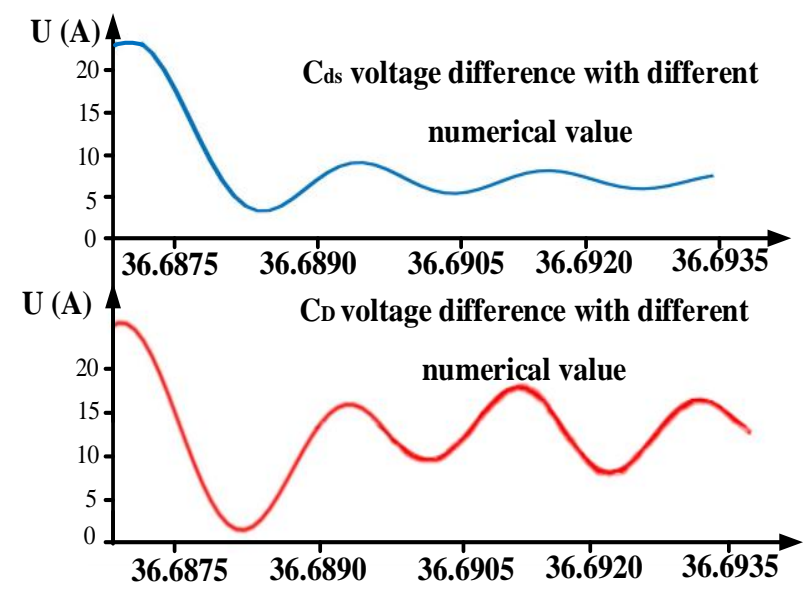

Figure 12. Waveforms of voltage stress with different parasitic parameter values.

\section{Simulations and Experiment Verification}

An experimental platform for the symmetric dual switch high-gain converter is built in the laboratory. The devices selections and parameter values settings of the experimental platform are shown in Table 1. 
Table 1. Parameter values of devices.

\begin{tabular}{cc}
\hline Components & Parameter Values \\
\hline$U_{i} / U_{o}$ & $30-50 \mathrm{~V} / 200 \mathrm{~V}$ \\
$F_{S}$ & $200 \mathrm{kHz}$ \\
$S_{1}, S_{2}$ & IRFP250 \\
$D$ & $S F 24$ \\
$C_{D}$ & $126 \mathrm{pF}$ \\
$L_{d 1}, L_{d 2}$ & $135 \mathrm{nH}$ \\
$L_{s 1}, L_{s 2}$ & $12 \mathrm{nH}$ \\
$C_{d s 1}, C_{d s 2}$ & $232 \mathrm{pF}$ \\
$R_{L}, R_{d}$ & $0.05 \Omega$ \\
$R_{s 1}, R_{s 2}$ & $0.1 \Omega$ \\
$C_{D 01}, C_{D 02}$ & $60 \mathrm{pF}$ \\
\hline
\end{tabular}

\subsection{Simulations in Saber}

The simulated waveforms of the inductor current, switch voltage and diode voltage are shown in Figure 13. The inductor current waveform shows a trend of first rising and then falling. The inductor current, MOSFET voltage, and diode voltage waveforms are all resonant. Compared with ideal conditions, the voltage amplitudes of MOSFETs and diodes are increased due to the influences of resonance when considering parasitic parameters under high-frequency conditions.

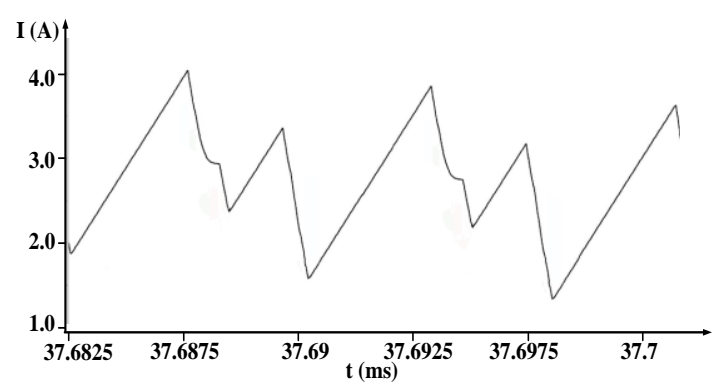

(a)

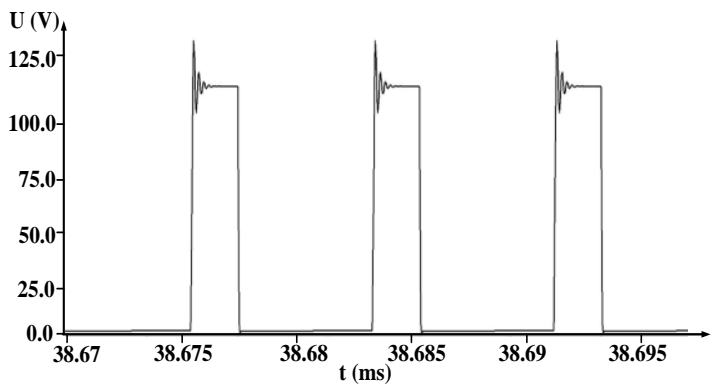

(b)

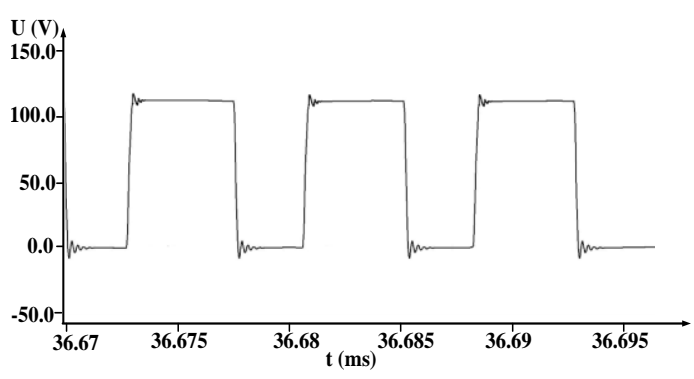

(c)

Figure 13. Circuit waveforms obtained through Saber simulation. (a) Simulation waveform of inductor current. (b) Simulation waveform of MOSFET (metal-oxide-semiconductor field-effect transistor) voltage. (c) Simulation waveform of diode voltage.

The simulation waveforms show that, due to the high-frequency resonance under high-frequency conditions, the amplitudes of inductor currents, MOSFET voltage and diode voltage all increases due to the parasitic capacitors resonate with the inductors in the sneak circuit, in line with the previous analysis. 


\subsection{Experimental Verification}

The experimental platform of the dual-switch high-gain converter built in the laboratory is shown in the Figure 14 below.

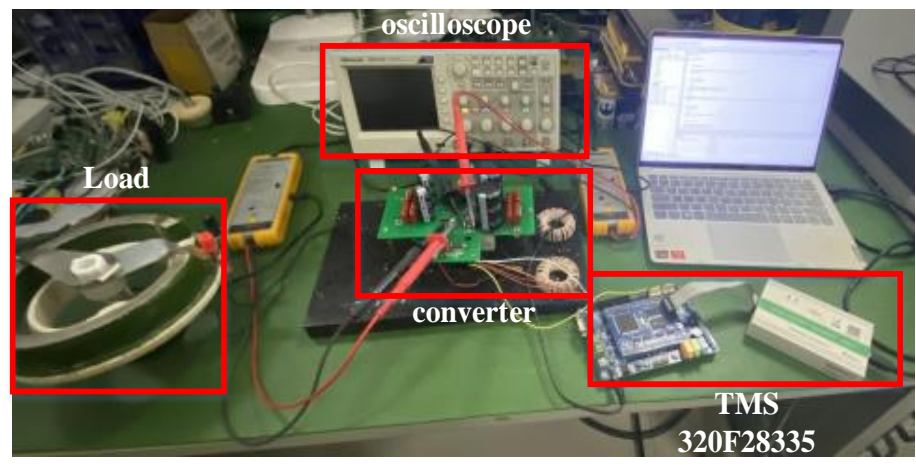

Figure 14. Experiment platform.

The parasitic parameter values of the devices are sot as $R_{S 1}=R_{S 2}=0.05 \Omega, C_{d s 1}=C_{d s 2}=232 \mathrm{pF}$, in the case of symmetrical parasitic parameters, the experimental waveforms of $P_{o}=200 \mathrm{~W}$ are shown in Figure 15.

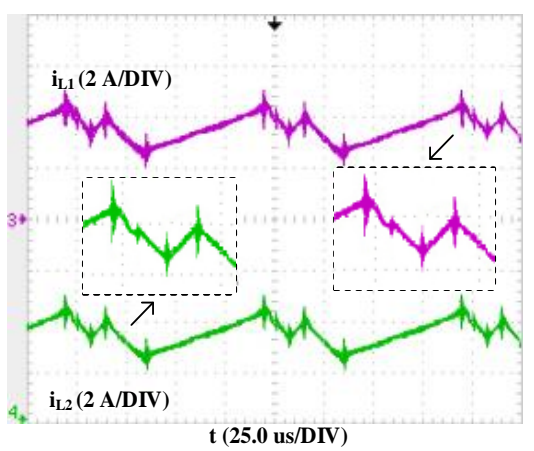

(a)

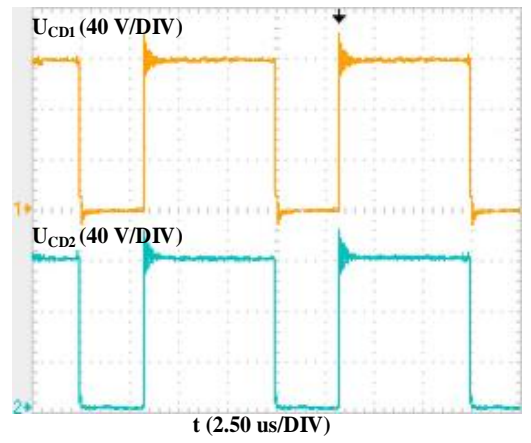

(c)

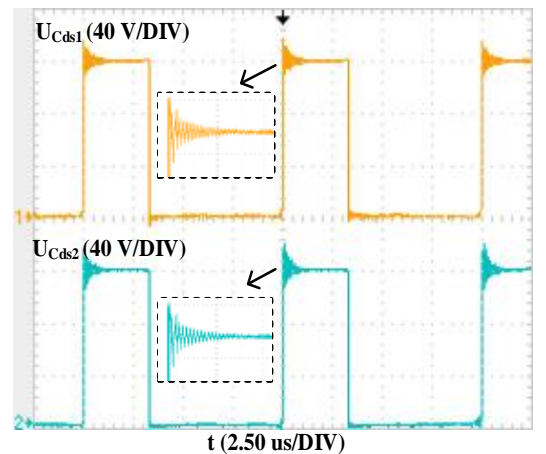

(b)

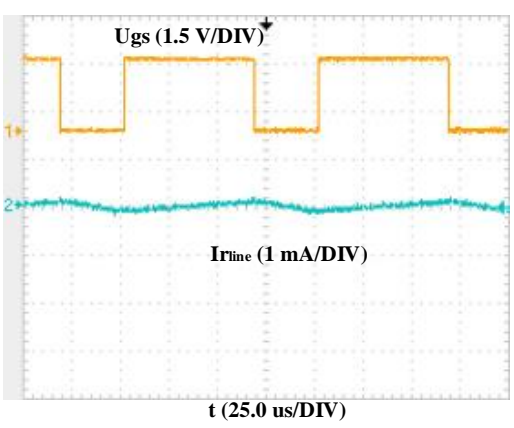

(d)

Figure 15. Experimental waveforms considering parasitic parameters for $P_{o}=200 \mathrm{~W}$. (a) Experimental waveform of inductor current. (b) Experimental waveform of MOSFET voltage. (c) Experimental waveform of diode voltage. (d) Experimental waveform of centerline current.

After the output power in the original experiment is adjusted from $200 \mathrm{~W}$ to $80 \mathrm{~W}$, the diagrams of the experimental waveforms of $P_{o}=80 \mathrm{~W}$ are shown in Figure 16. From the diagrams of the 
experimental waveforms, the amplitude of the current resonance reduces $0.4 \mathrm{~A}$, and the amplitude of the MOSFET voltage reduces $8.5 \mathrm{~V}$, which confirms the theoretical analysis.

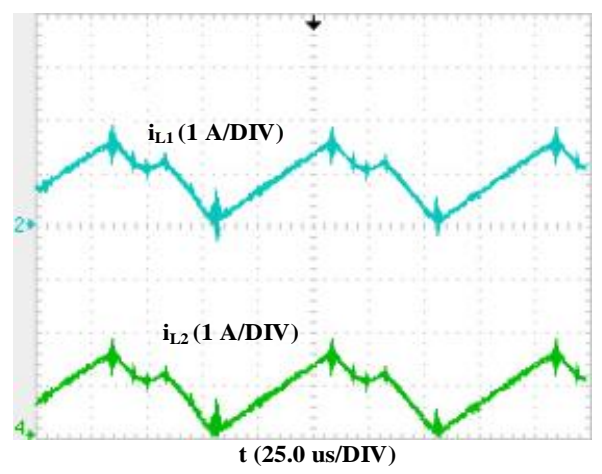

(a)

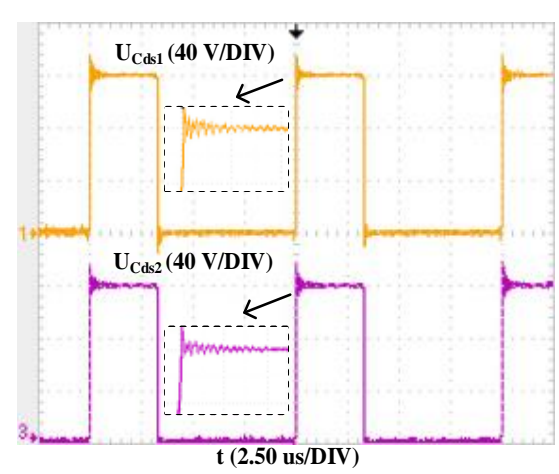

(b)

Figure 16. Experimental waveforms considering parasitic parameters for $P_{o}=80 \mathrm{~W}$. (a) Inductor current experimental waveform. (b) MOSFET voltage $\left(U_{C d s}\right)$ experimental waveform.

To verify the effects of different parasitic parameter values of the same type of devices on the converter under high-frequency conditions, the value of the parasitic resistance $R_{L 2}$ is adjusted from $0.05 \Omega$ to $0.1 \Omega$. The experimental waveforms of $P_{o}=200 \mathrm{~W}$ are shown in Figure 17 below.

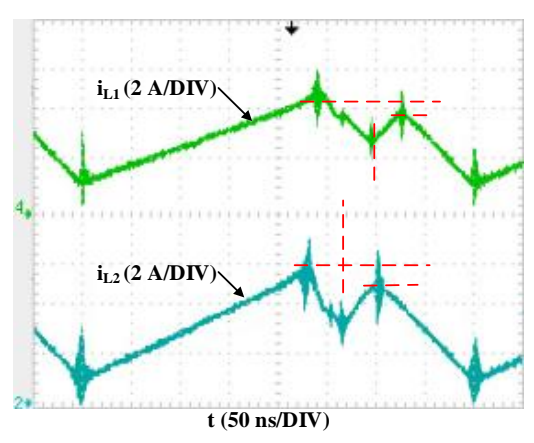

(a)

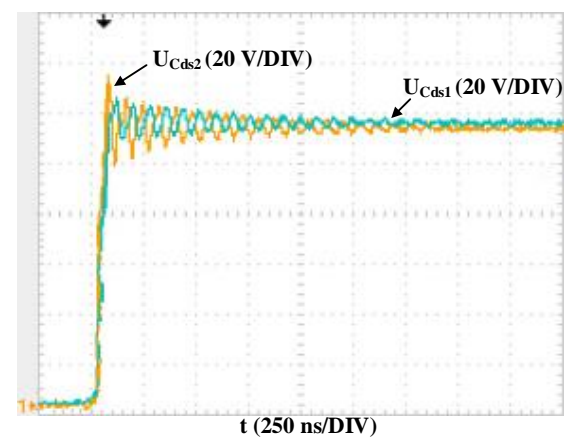

(c)

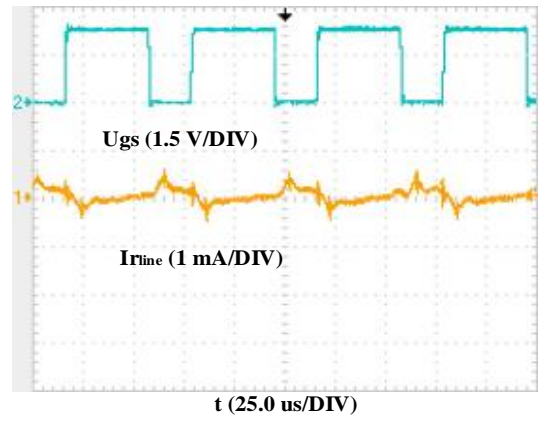

(b)

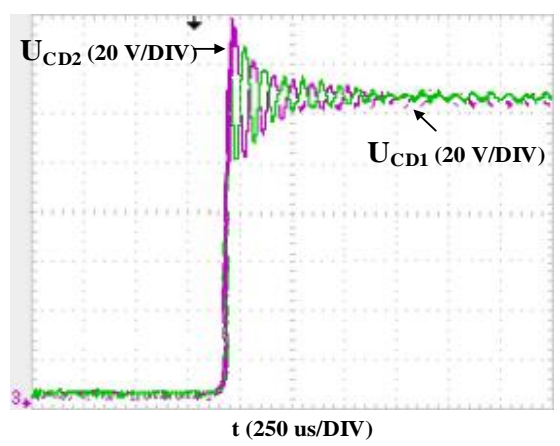

(d)

Figure 17. Experimental waveforms considering parasitic parameters for $P_{o}=200 \mathrm{~W}$ after the parasitic parameter $R_{L 2}$ value is changed. (a) Experimental waveform of inductor current. (b) Experimental waveform of centerline current. (c) Experimental waveform of MOSFET voltages. (d) Experimental waveform of diode voltages. 


\subsection{Comparative Analysis of Simulation and Experimental Waveforms}

The resonance current amplitudes values in experimental waveforms Figure $15 \mathrm{a}$ are $i_{L 1}=8.8 \mathrm{~A}$, $i_{L 2}=8.7 \mathrm{~A}$, and resonance current amplitudes values in simulation waveforms Figure 13a are $i_{L 1}=8.9 \mathrm{~A}$, $i_{L 2}=8.7 \mathrm{~A}$. The amplitudes are almost the same.

By comparing the experimental waveforms, the simulation waveforms, and theoretical analysis of the inductor currents, it can be known that the analysis of the influences of the parasitic parameters on the inductor currents is in line with the actual working situations.

The resonance voltage amplitudes values in experimental waveforms Figure $15 \mathrm{~b}$ are $U_{C d s 1}=188 \mathrm{~V}$, $U_{C d s 2}=183 \mathrm{~V}$, and voltage amplitudes values in simulation waveforms Figure $13 \mathrm{~b}$ are $U_{C d s 1}=187 \mathrm{~V}$, $U_{C d s 2}=184 \mathrm{~V}$. The experimental waveforms of MOSFETs resonant voltages are consistent with the simulated waveforms.

From above analysis, it can be known that the parasitic capacitors and the inductors in the circuit resonate under high-frequency conditions, and the amplitudes of the voltages are increased by the influences of resonance, which is consistent with the conclusions obtained from theoretical analysis.

From the above experimental waveform Figure 17a, it can be seen that the resonance current peak value of the inductor current $i_{L 2}$ is enhanced by $0.64 \mathrm{~A}$ compared to $i_{L 1}$, and the appearance time is advanced by 8.3 us. Since the inductor currents $i_{L 1}$ and $i_{L 2}$ no longer maintain the same phase and amplitude, the centerline will have charge and discharge currents. Experimental waveform Figure 17b shows the current in the converter centerline to prove this conclusion. Through the above analysis of the experimental waveforms of the inductor currents $i_{L 1}$ and $i_{L 2}$ in the asymmetric condition, it can be known that the symmetry of the ideal symmetric dual switch high-gain converter will be destroyed and the dynamic balance characteristics of converters will be affected when considering parasitic parameters under high-frequency conditions.

From the experimental waveform Figure 17c, it can be seen that the peak value of the resonance voltage $U_{C d s 2}$ increases by $7 \mathrm{~V}$ than $U_{C d s 1}$, and the phases of the two voltages $U_{C d s 1}, U_{C d s 2}$ are no longer the same. From the waveform Figure 17d, it can be seen that the peak value of the resonance voltage $U_{C D 02}$ increases by $13 \mathrm{~V}$ than $U_{C D 01}$, and the phases of the two voltages $U_{C D 01}, U_{C D 02}$ are different. Through the above analysis, it can be known that the amplitudes of the resonance voltages of MOSFETs and diodes no longer maintains the same values after considering the parasitic parameters values asymmetry, which puts more precise requirements for the selection of devices and the selection of device-rated voltages in actual applications.

From the above experimental waveforms, it can be seen when the values of the parasitic parameters become larger, the voltage stress values of the corresponding switches will be greater. Through the comparisons of experimental waveforms with the same and different parasitic parameter values, it can be seen that when the parasitic parameter values of the devices are different, the symmetry of the ideal symmetric dual switch high-gain converter will be destroyed and the dynamic balance characteristics of converters will be affected and the resonance voltages amplitudes of the MOSFETs are no longer the same, which puts more precise requirements for the selections of devices and the selections of device rated voltages in actual high-frequency application conditions.

A comparison of voltage gains obtained from the experiment and calculation is shown in Figure 18. 


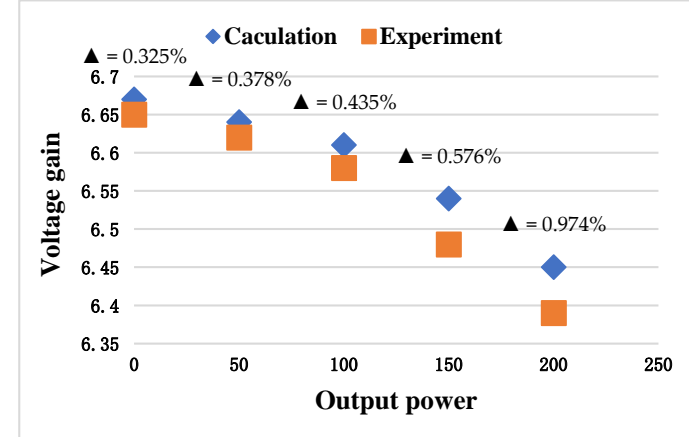

(a)

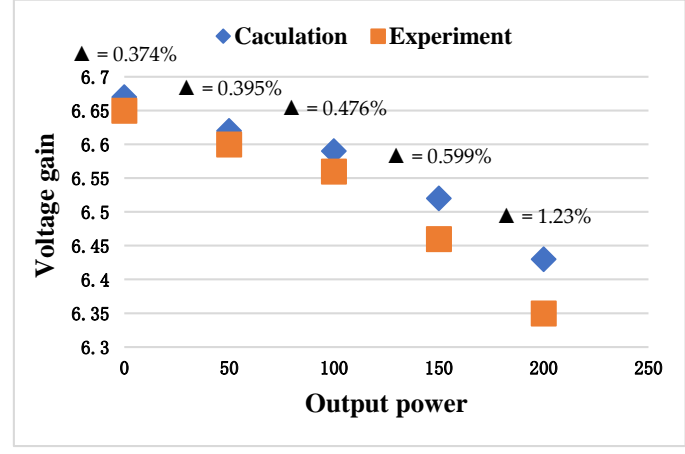

(b)

Figure 18. Experimental and calculated voltage gain under different cases. (a) Condition 1. (b) Condition 2.

In Condition 1, the values of parasitic parameters are: $C_{d s}=232 \mathrm{pF}, C_{D}=60 \mathrm{pF}, R_{s}=0.05 \Omega$, $L_{e}=147 \mathrm{nH}$. In Condition 2, the values of parasitic parameters are: $C_{d s}=232 \mathrm{pF}, C_{D}=120 \mathrm{pF}$, $R_{S}=0.1 \Omega, L_{e}=147 \mathrm{nH}$. The different values in Figure 18 are acquired by adding external capacitors, inductors, and resistors across the device terminals. Figure 18 proves that by varying the values of parasitic parameters while other parameters remain unchanged, the greater the parasitic parameter values, the more obvious the impacts on the output gain, which consistent with theoretical results. The results of the theoretical analysis and experiments verify that the sneak circuit phenomena can be reduced by choosing the value of parameters appropriately, which means higher requirements for the selection and optimization of power devices.

\section{Conclusions}

This paper takes the symmetrical dual-tube high-gain converter as the research object, and analyzes the characteristics of the high-frequency down-converter considering the parasitic parameters. A model of the symmetrical dual-switch high-gain converter considering parasitic parameters is established, and two sneak operating modes-Sneak Mode 1 and Sneak Mode 2-are found through sneak circuit analysis. Through the analysis of operating characteristics, it is found that considering the parasitic parameters of devices such as $C_{d s}, C_{D}, R_{L}, L_{S}, L_{d}$, and $R_{S}$ under high frequency will reduce the voltage gain, increase the switching stress, and affect the symmetry of the circuit operation when the parasitic parameter values are different. Finally, the conclusions obtained through simulation and experiment are consistent with the theoretical analysis, which proves the correctness of the above analysis. The analysis of the working characteristics of the converter under high frequency in this paper has certain reference value for the selection of devices and the selection of margin under high frequency.

Author Contributions: Methodology, H.T.; software, H.T.; validation, D.K.; formal analysis, H.T.; investigation, Y.T.; resources, H.T.; data curation, D.K.; writing—original draft preparation, D.K.; writing—review and editing, D.K.; visualization, H.T.; supervision, H.T. All authors have read and agreed to the published version of the manuscript.

Funding: This work was funded by the National Natural Science Foundation of China under Grant 51677084, The Hebei Province Science Fund for Distinguished Young Scholars grant number E2020202140, and in part by Support Program (III) for 100 Outstanding Innovative Talents in Universities of Hebei Province under Grant SLRC2019025.

Conflicts of Interest: The authors declare no conflict of interest. 


\section{References}

1. Han, J.; Gu, X.; Yang, Y.; Tang, T. Dynamic Improvement with a Feedforward Control Strategy of Bidirectional DC-DC Converter for Battery Charging and Discharging. Electronics 2020, 9, 1738. [CrossRef]

2. Zhang, B.; Qiu, D. Sneak circuits in power converters: Concept, principle and application in CPSS Transactions on Power Electronics and Applications. CPSS Trans. Power Electron. Appl. 2017, 2, 68-75. [CrossRef]

3. Hongchen, L.; Li, F. Novel High Step-Up DC-DC Converter with Active Coupled-Inductor Network for a Sustainable Energy System. IEEE Trans. Power Electron. 2015, 30, 6476-6482.

4. Liu, G.; Zhao, P.; Zhao, M.; Yang, Z.; Chen, H. Electromagnetic Disturbed Mechanism of Electronic Current Transformer Acquisition Card under High Frequency Electromagnetic Interference. Electronics 2020, 9, 1293. [CrossRef]

5. Li, M.; Zhang, B.; Qiu, D. Sneak circuit analysis of Boost converter considering parasitic parameters. In Proceedings of the Applied Power Electronics Conference \& Exposition, IEEE, Fort Worth, TX, USA, 16-20 March 2014.

6. Tang, Y.; Wang, T.; He, Y.; Fu, D. Study of a high step-up voltage gain DC/DC converter with passive lossless clamp circuit. In Proceedings of the IEEE IECON, Vienna, Austria, 10-13 November 2013; pp. 1308-1313.

7. Shen, C.-L.; Chen, L.-Z.; Chen, H.-Y. Dual-Input Isolated DC-DC Converter with Ultra-High Step-Up Ability Based on Sheppard Taylor Circuit. Electronics 2019, 8, 1125. [CrossRef]

8. Zhao, B.; Song, Q.; Li, J.; Liu, W.; Liu, G.; Zhao, Y. High-Frequency-Link DC Transformer Based on Switched Capacitor for Medium-Voltage DC Power Distribution Application. IEEE Trans. Power Electron. 2016, 31, 4766-4777. [CrossRef]

9. Zhang, B.; Qiu, D.Y. Sneak Circuits of Power Electronic Converters; Wiley: New York, NY, USA, 2015.

10. Zhaksylyk, Y.; Halvorsen, E.; Hanke, U.; Azadmehr, M. Analysis of Fundamental Differences between Capacitive and Inductive Impedance Matching for Inductive Wireless Power Transfer. Electronics 2020, 9, 476. [CrossRef]

11. Rogina, M.R.; Rodríguez, A.; Vázquez, A.; Lamar, D.G.; Hernando, M.M. Event-Focused Digital Control to Keep High Efficiency in a Wide Power Range in a SiC-Based Synchronous DC/DC Boost Converter. Electronics 2020, 9, 2154. [CrossRef]

12. Ansari, S.A.; Moghani, J.S. A Novel High Voltage Gain Noncoupled Inductor SEPIC Converter. IEEE Trans. Ind. Electron. 2018, 66, 7099-7108. [CrossRef]

13. Ragab, K.; Kozak, M.; Sun, N. Thermal Noise Analysis of a Programmable-Gain Switched-Capacitor Amplifier with Input Offset Cancellation. IEEE Trans. Circuits Syst. II Express Briefs 2013, 60, 147-151. [CrossRef]

14. Muhammad, M.; Armstrong, M.; Elgendy, M.A. A Nonisolated Interleaved Boost Converter for High-Voltage Gain Applications. IEEE J. Emerg. Sel. Top. Power Electron. 2016, 4, 352-362. [CrossRef]

15. Gutsmann, B.; Mourick, P.; Silber, D. Exact inductive parasitic extraction for analysis of IGBT parallel switching including DCB-backside eddy currents. In Proceedings of the 2000 IEEE 31st Annual Power Electronics Specialists Conference, Galway, Ireland, 23 June 2000.

16. Chen, Z.; Boroyevich, D.; Burgos, R. Experimental parametric study of the parasitic inductance influence on MOSFET switching characteristics. In Proceedings of the 2010 International Power Electronics Conference-ECCE ASIA, Sapporo, Japan, 21-24 June 2010.

17. Xiong, F.; Zhang, J.M.; Qian, Z.M. Effect of parasitic parameters on current distortion of boost PFC circuit. Proc. CSEE 2010, 30, 40-47.

18. Li, M.; Zhang, B.; Qiu, D.; Zhang, G. Sneak Circuit Phenomena in a DCM Boost Converter Considering Parasitic Parameters. IEEE Trans. Power Electron. 2017, 32, 3946-3958. [CrossRef]

Publisher's Note: MDPI stays neutral with regard to jurisdictional claims in published maps and institutional affiliations. 